\title{
METODOLOGIA SENAI PARA FORMAÇÃO PROFISSIONAL COM BASE EM COMPETÊNCIAS: UM ESTUDO DE CASO SOBRE A IMPLANTAÇÃO DESTE METODO NO DEPARTAMENTO REGIONAL DO SENAI DE SANTA CATARINA
}

Osvair Almeida Matos ${ }^{1}$

Sérgio Roberto Arruda²

\begin{abstract}
RESUMO
Este artigo busca identificar quais as estratégias, decorrentes da implantação da metodologia SENAI de formação profissional com base em competências, contribuem de forma significativa para o processo de ensino e aprendizagem dos alunos do SENAI/SC. Neste sentido, foramidentificadasas principais estratégias empregadas pela instituição, os resultados alcançados a partir da implementação das estratégias mais relevantes, e as contribuições para o processo de ensino e aprendizagem. $O$ estudo consiste em uma pesquisa cuja abordagem é descritiva e de enfoque qualitativo na forma de estudo de caso. Foi possível constatar que a instituição adota ações de implementação da metodologia desde 1999 e que muitos programas corporativos são decorrentes desta implementação, tais como: Programa Conexão, Programa Educação em Movimento, e Academia SENAI. Destaca-se também um número expressivo de eventos e capacitações oferecidaspela instituição para os colaboradores. Portanto, conclui-se que a implementação da metodologia SENAI de formação profissional com base em competênciaspassa pelo desenvolvimento de ações que visama criação de uma cultura focada no desenvolvimento de competências para toda a instituição.
\end{abstract}

Palavras-chave: Formação profissional. Metodologia baseada em competências. Perfil profissional. Desenho curricular. Prática pedagógica.

\footnotetext{
${ }^{1}$ Especialista, e-mail: osvair@sc.senai.br

${ }^{2}$ Mestre, e-mail: arruda@sc.senai.br
} 


\section{INTRODUÇÃO}

O presente estudo aborda as estratégias de implementação empregadas pelo Serviço Nacional de Aprendizagem Industrial - Departamento Regional de Santa Catarina (SENAI/ SC) - na implantação da "Metodologia SENAI de Formação Profissional Com Base Em Competências", em suas unidades educacionais no estado. Este método é uma forma de superar as barreiras que surgem no novo contexto sócio econômico - caracterizado pela necessidade de produtividade, eficiência,competitividade,inovação e sustentabilidade - Este contexto requer profissionais capacitados, com competências para atuar em diferentessegmentos econômicos. Para a Federação das Indústrias do Estado de Santa Catarina $(2012$, p.7) "é cada vez mais evidente o esforço da indústria para manter a competitividade e garantir participação no mercado". Entre as estratégias utilizadas para o alcance dos objetivos têm-se a busca por maior eficiência nos processos, a melhora na qualidade dos produtos e serviços, a atualização tecnológica e a inovação.

De acordo com Serviço Nacional de Aprendizagem Industrial (2009a, p. 7), "o mundo do trabalho passa por mudanças significativas, que":

[...] repercutem profundamente no mundo da educação. A generalização do uso e aplicações da microinformática; a compreensão do trabalho como algo além de conhecimentos técnicos, envolvendo habilidades comunicativas e comportamentais; a necessidade da transferência de conhecimentos entre áreas profissionais distintas - todos esses elementos exigem a estruturação de uma educação profissional dinâmica, renovada, em sintonia constante com os movimentos do setor produtivo.

O Projeto Estratégico do SENAI Nacional "Metodologias para Formação com Base em Competências" é uma resposta da instituição às mudanças que surgem no mundo do trabalho e que repercutem no mundo da educação.

A formação com base em competências é um tema bastante utilizado nos dias atuais, principalmente, a partir da promulgação da Resolução no 4 do Conselho Nacional de Educação, em que define a competência profissional como: "a capacidade de mobilizar, articular e colocar em ação valores, conhecimentos e habilidades necessários para o desempenho eficiente e eficaz de atividades requeridas pela natureza do trabalho" (BRASIL, 1999b, p. 2).

O termo competências tem sido definido como "capacidade de agir eficazmente em um determinado tipo de situação, apoiada em conhecimentos, mas sem limitar-se a eles" (PERRENOUD, 1999, p. 7). Para Fleury e Fleury (2001, p. 184) "competência é uma palavra do senso comum, utilizada para designar uma pessoa qualificada para realizar alguma coisa". Segundo Moretto (2009) competência é a capacidade do sujeito mobilizar recursos para abordar e resolver situações complexas.

O presente estudo está direcionado para o seguinte problema de pesquisa: Quais as estratégias, decorrentes da implantação da metodologia SENAI de formação 
profissional com base em competências, que contribuem de forma significativa para o processo de ensino e aprendizagem dos alunos? O objetivo deste estudo é analisar os impactos no processo educacional, decorrentes das estratégias de implantação da metodologia SENAI de formação profissional com base em competências.

Efetivamente, o presente estudo visa atender os seguintes objetivos específicos:

a) identificar as principais estratégias empregadas pelo SENAI/SC na implantação da metodologia de formação profissional com base em competências;

b) identificar os resultados alcançados a partir da implementação das estratégias mais relevantes;

c) apresentar as contribuições destas estratégias para o processo de ensino e aprendizagem.

\section{FUNDAMENTAÇÃO TEÓRICA}

\subsection{Formação profissional}

A formação profissional é um conjunto de atividades que visa à aquisição de conhecimentos, capacidades, e competências sócia- cultural exigida para o exercício das funções próprias de uma profissão ou grupo de profissões, em qualquer ramo de atividade econômica (ANTUNES et al., 2001).

De acordo com o dicionário da língua portuguesa a palavra formação pode significar:

1. Ato, efeito ou modo de formar. 2. Constituição, caráter. 3. Maneira por que se constituiu uma mentalidade, um caráter, ou um conhecimento profissional[...].(FERREIRA, 2009, p. 923).

Enquanto que a palavra profissional significa:

1.Respeitante ou pertencente a profissão, ou a certa profissão: ensino profissional [...]. 2.Que exerce uma atividade por profissão ou ofício[...].3.Dizse do que é necessário ao exercício de uma profissão, ou próprio dela. 4.Deprec. Diz-se de pessoa voltada habitualmente para certa atividade como se fosse ela ofício ou profissão: carreirista profissional [...]. 5.Bras. Pessoa que exerce uma atividade por ofício(FERREIRA, 2009, p.1637).

Para o Serviço Nacional de Aprendizagem Industrial (1997 apud MORAES 2000) a formação profissional deve responder às particularidadesregionais e à necessidade de os indivíduos poderem construir sua formação no decorrer do tempo, agregando novos conteúdos que ampliem suas competências e que facilitem sua inserção e permanência no mundo do trabalho. 
A Organização das Nações Unidas para a Educação, Ciência e Cultura (1998, p. 136), esclarece que:

a formação profissional deve conciliar dois objetivos divergentes: a preparação para os empregos existentes atualmente e uma capacidade de adaptação a empregos que ainda nem sequer podemos imaginar.

Para a Secretaria de Inspeção do Trabalho,a formação profissional esta relacionada às funções exercidas no mundo do trabalho, em consonância com os seguintes fatores:

\footnotetext{
I - o nível das capacidades profissionais e dos conhecimentos técnico-teóricos requeridos para o exercício da atividade profissional;

II - a duração do período de formação necessário para a aquisição das competências e habilidades requeridas; e

III - a adequação da função às necessidades da dinâmica de um mercado de trabalho em constante mutação. [...] (BRASIL, 2002)
}

Entende-se que a formação profissional é a oportunidade do indivíduo ser inserido no mundo do trabalho, garantindo não somente o acesso, mas, principalmente, sua permanência. Esta permanência se dá por meio do desenvolvimento de competências profissionais requeridas pelas funções exercidas no mundo do trabalho.

\subsection{Competências Profissionais}

O termo "competência", etimologicamente, é de origem latina "competentes" que significa que vai com; o que está adequado a. Este termo foi utilizado em 1955, por Chomsky, quando surgiu a expressão "competência linguística", sendo então empregada em combate ao behaviorismo (CANTO, 2008).

Conforme Fleury e Fleury (2001), o debate a respeito de competências nasceu na França nos anos 70. A iniciativa foi decorrente do questionamento do conceito de qualificação e do processo de formação profissional. Observou-se naquele período um descompasso entre as necessidades do mundo do trabalho e o ensino das necessidades reais das empresas, visando a aumentar a capacitação dos trabalhadores e consequentemente, suas chances de empregabilidade.

Durante a década de 80 , estudos realizados sobre as competências gerenciais, identificaram um conjunto de características e traços que definem um desempenho superior (FLEURY; FLEURY, 2001). Nesta perspectiva, o conceito de competência é pensado como conjunto de capacidades específica, e sociais que justificam um alto desempenho, acreditando-se que os melhores desempenhos estão fundamentados na inteligência e personalidade das pessoas. Desta forma, a competência é entendida como estoque de recursos, que o indivíduo detém (FLEURY; FLEURY, 2001). Embora o foco de análise 
seja o indivíduo, a maioria dos autores americanos sinaliza a importância de alinhar as competências às necessidades estabelecidas pelas funções existentes nas organizações. (FLEURY; FLEURY, 2001).

No Brasil o modelo de competências surgiu:

\begin{abstract}
com as reformas educacionais, que por sua vez eram parte do conjunto de reformas estruturais do Estado. Essas reformas decorrentes do ajuste macroeconômico que os países latino-americanos se submeteram ao longo de 1990 para superar a inflação e estagnação e retornar o crescimento econômico interrompido na década de 1980. (DELUIZ apud VIEIRA, 2010).
\end{abstract}

Segundo Brasil (1999b) ser competente profissionalmente implica na capacidade pessoal de mobilizar, articular e colocar em ação conhecimentos, habilidades, atitudes e valores necessários para o desempenho eficiente e eficaz de atividades requeridas pela natureza do trabalho e pelo desenvolvimento tecnológico.O conceito de competências remete, então, à capacidade de mobilizar conhecimentos para a ação.

De acordo com o dicionário de língua portuguesa competência é:

[...] a qualidade de quem é capaz de apreciar e resolver certo assunto, fazer determinada coisa; capacidade, habilidade, aptidão, idoneidade [...]. (FERREIRA, 2009, 508).

Para o Serviço Nacional de Aprendizagem Industrial (2009a, p.48):

a competência profissional é a mobilização de conhecimentos, habilidades e atitudes profissionais necessários ao desempenho de atividades ou funções típicas, segundo padrões de qualidade e produtividade requeridos pela natureza do trabalho.

De acordo com Perrenoud (1999 apud SERVIÇO NACIONAL DE APRENDIZAGEM INDUSTRIAL, 2009c, p. 10) "Revolução das Competências" só acontecerá se, durante a formação profissional, os futuros (e atuais) docentes experimentarem-na pessoalmente.

\title{
2.3 A metodologia SENAI para formação profissional com base em competências
}

A "Metodologia SENAI para Formação Profissional com Base em Competências"foi concebida a partir de 1999, por técnicos de nove Departamentos Regionais do SENAI Bahia, Distrito Federal, Minas Gerais, Paraná, Pernambuco, Rio de Janeiro, Rio Grande do Sul, Santa Catarina e São Paulo - sob a coordenação do Departamento Nacional do SENAI. Esses técnicos, foram orientados por consultorias da Espanha (Instituto Nacional do Empleo - INEM) e da Organização Internacional do Trabalho/Centro Inter-Americano para o desenvolvimento de conhecimento na formação profissional (OIT/CINTERFOR). Este grupo pesquisou, discutiu, propôs a base teórica paraimplementação de experiênciapiloto para consolidar a proposta metodológica do SENAI para Formação com Base em Competências (SERVIÇO NACIONAL DE APRENDIZAGEM INDUSTRIAL, 2009a). 
A primeira publicação se deu em 2002, em quatro volumes. Atualmente esta metodologia é composta por três documentos basilares.

O primeiro refere-se à elaboração de um Perfil Profissional que identifica as competências profissionais no âmbito de uma qualificação pré-definida. Este perfil é elaborado por um comitê técnico setorial composto por segmentos internos e externos ao SENAI.

O segundo documento é referente ao Desenho Curricular, ou seja, a transposição das competências profissionais do mundo do trabalho, definidas no perfil profissional, para a educação. Nesta fase, as competências profissionais são traduzidas em capacidade técnicas, sociais, organizativas e metodológicas.

O Norteador da Prática Pedagógica completa esta trilogia de documentos basilares. Este documento objetiva auxiliar o docente na implementação do plano de curso por meio do planejamento de práticas pedagógicas, visando o desenvolvimento das capacidades decorrentes do desenho curricular.

A seguir é apresenta-se, com mais detalhes, estes documentos basilares.

\section{Perfil Profissional}

De acordo com o Conselho Nacional de Educação, torna-se cada vez mais importante que o técnico tenha um perfil de qualificação que lhe permita construir itinerários profissionais, com mobilidade, ao longo de sua vida produtiva. Este perfil é definidor da identidade do curso e será estabelecido levando-se em conta as competências profissionais gerais da qualificação de uma ou mais áreas, completadas com outras competências específicas, em função das condições locais e regionais, sempre direcionadas para a laborabilidade frente às mudanças, o que supõe polivalência profissional (BRASIL, 1999a).

Para o Serviço Nacional de Aprendizagem Industrial (2009a), o perfil profissional é a descrição do que idealmente é necessário saber realizar no campo profissional, sendo expresso em termos de competências profissionais. Sua elaboração acontece por meio de um Comitê Técnico Setorial. Este comitê é um fórum técnico-consultivo, destinado à discussão de assuntos referentes aos nexos entre a educação e o trabalho, sendo constituída por profissionais de segmentos internos e externos aorganização, cuja experiência profissional contribui para orientar a tomada de decisão referente ao desenvolvimento das ações de educação. Este comitê tem por objetivo contribuir para a identificação e atualização permanente de competências profissionais.

O perfil profissional definido pelo comitê técnico setorial configura-se como uma etapa inicial no desenvolvimento do processo de ensino e aprendizagem, pois é o ponto de partida para a construção de um currículo que pode propiciar o desenvolvimento de práticas pedagógicas inovadoras. 


\section{Desenho Curricular}

A partir das demandas do mundo do trabalho e da sociedade, elabora-se o perfil profissional de conclusão da habilitação ou qualificação pré-definida, este documento deve subsidiar a construção do currículo do curso (BRASIL, 1999b).

Neste contexto, o Serviço Nacional de Aprendizagem Industrial (2009b, p.13) estrutura o desenho curricular do curso como:

[...] concepção da oferta formativa que deve propiciar o desenvolvimento das competências constitutivas do perfil profissional estabelecido pelo comitê. Trata-se da decodificação de informações do mundo do trabalho para o mundo da educação, traduzindo-se pedagogicamente as competências de um perfil profissional.

A elaboração do desenho curricular inicia-se pela análise do perfil profissional, em que são definidos os fundamentos técnicos e científicos, as capacidades técnicas, sociais, organizativas, metodológicas.Após a análise do perfil profissional, são definidos os módulos que integrarão a oferta formativa.

Segundo o Serviço Nacional de Aprendizagem Industrial (2009b, p.23), módulo é:

[...]um conjunto didático-pedagógico sistematicamente organizado para o desenvolvimento de competências profissionais significativas. Prevê módulos preparatórios à qualificação profissional, definidos no âmbito dessa metodologia como [...], módulos com terminalidade, que qualificam e permitem o exercício profissional, e módulos sem terminalidade, objetivando estudos subsequentes.

Uma vez definidos os módulos, procede-se à estruturação das unidades curriculares que são as unidades pedagógicas que compõe o currículo, constituída numa visão interdisciplinar e independente em termos formativos e de avaliação, durante os processos de ensino e aprendizagem (SERVIÇO NACIONAL DE APRENDIZAGEM INDUSTRIAL, 2009b).

Na sequência, define-se o itinerário formativo que é o percurso ou a sequência de desenvolvimento proposta para o conjunto de módulos relativos a uma qualificação ou área profissional que, ordenados pedagogicamente, capacitam para o exercício do trabalho, tendo-se em vista, quando for o caso, as diversas terminalidades contidas no perfil profissional (SERVIÇO NACIONAL DE APRENDIZAGEM INDUSTRIAL, 2009a).

A última etapa na elaboração do desenho curricular é o plano de curso que é parte integrante da proposta pedagógica, tendo por finalidade garantir a organização e continuidade do curso. Assim, ao final do processo de elaboração da oferta formativa, a equipe técnico-pedagógica deve redigir um plano de curso, que consolide todas as decisões curriculares tomadas. 


\section{Norteador da Prática Pedagógica}

A prática profissional constitui e organiza o currículo, o que evidencia a centralidade desse aspecto. Por meio de uma visão ampliada do que seja prática profissional - toda oportunidade de colocar em ação o aprendizado - percebe-se a importância de tratar os fundamentos técnicos, científicos e as bases tecnológicas a partir de situações que reflitam os contextos de cada profissão (BRASIL, 1999b).

Segundo o Serviço Nacional de Aprendizagem Industrial (2009c, p.22) integrar a teoria e prática:

não se esgota nas relações que se estabelecem entre as duas dimensões. É necessário ir além, através da capacidade que permita ao aluno ter um olhar atento sobre os seus próprios processos de raciocínio. Isto o habilitará a explicitar e avaliar caminhos e alternativas pelos quais optou na resolução de problemas.

Para uma prática pedagógica eficaz, elegem-se alguns princípios facilitadores de uma aprendizagem significativa: a interdisciplinaridade, contextualização, desenvolvimento de capacidades, aprender a aprender,aproximar a formação ao mundo real, ao trabalho e às práticas sociais,integrar teoria e prática,avaliação da aprendizagem e afetividade (SERVIÇO NACIONAL DE APRENDIZAGEM INDUSTRIAL, 2009c).

Neste contexto, o docente assume papel fundamental no desenvolvimento das práticas pedagógicas, pois é o mediador no processo de ensino e aprendizagem. Segundo Perrenoud (1999 apud SERVIÇO NACIONAL DE APRENDIZAGEM INDUSTRIAL 2009c, p. 18) o docente deve:

[...] abrir mão radicalmente do uso da avaliação como meio de pressão e de barganha; desistir de padronizar a avaliação e de abrigar-se atrás de uma equidade puramente formal;[...] exigir e conceder a confiança necessária para estabelecer um balanço de competências, apoiado mais em julgamento especializado do que em tarefa [...]; saber criar momentos de avaliação em situações mais amplas; saber e querer envolver os alunos na avaliação de suas competências, explicitando e debatendo os objetivos e os critérios, favorecendo a avaliação mútua, os balanços de conhecimento e a autoavaliação.

O Norteador da prática pedagógica é um documento de referência para a equipe técnico-pedagógica da instituição. Este documento aponta fundamentos sobre o repensar no processo educacional diante dos novos desafios impostos pela sociedade em transformação. Além disso, o norteador da prática pedagógica contribui para o fortalecimento da autonomia docente (SERVIÇO NACIONAL DE APRENDIZAGEM INDUSTRIAL, 2009c).

É no planejamento docente, de acordo com os princípios e diretrizes do Norteador da Prática Pedagógica, que o desenho curricular com base em competências se completa. 
A figura 1 exibe o fluxo simplificado da metodologia SENAI de Formação Profissional com Base em Competências. Este fluxo apresenta as etapas de elaboração de um curso de formação profissional na organização.

Figura 1: Fluxo da metodología de formação profissional com base em competências.

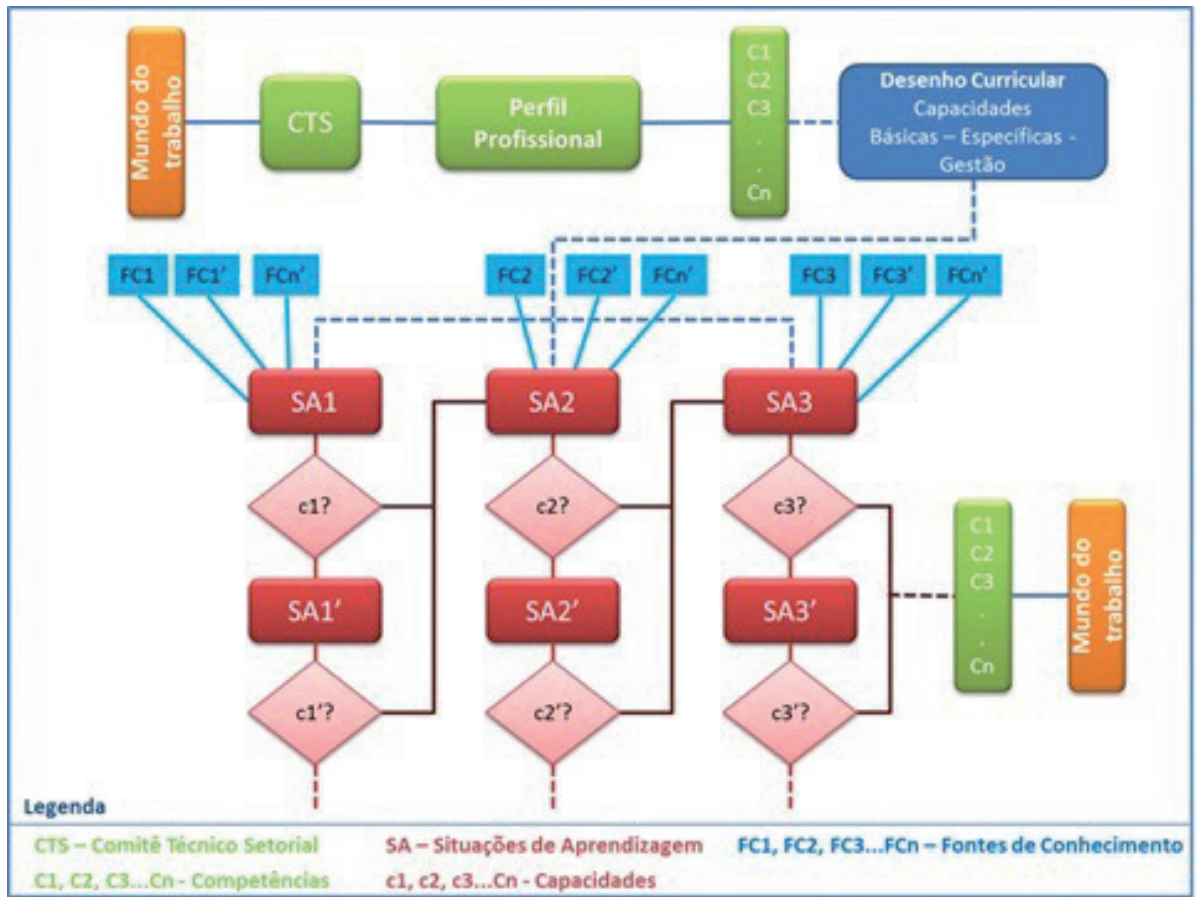

Fonte: Dos autores (2012)

Ressalta-se na figura supracitada,a etapa de desenvolvimento de situações de aprendizagem. As situações de aprendizagem definidas como atividades desafiadoras que, planejada pedagogicamente, considera a intersecção entre o difícil e o possível para o aluno realizar num determinado momento (SERVIÇO NACIONAL DE APRENDIZAGEM INDUSTRIAL, 2009c). Estas situações visam o desenvolvimento de capacidades profissionais que levem o aluno a se apropriar das competências definidas no perfil profissional, durante o seu processo formativo.

Cada situação de aprendizagem remete ao desenvolvimento de capacidades técnicas, sociais, organizativas e metodológicas, decorrentes da análise do perfil profissional. $\mathrm{Na}$ figura 1, observa-se que o desenvolvimento de situações de aprendizagem, ocorre de forma interativa durante a etapa de execução da formação profissional. Esta interação ocorre durante o planejamento das situações de aprendizagem, tendo em vista que o não atendimento dos critérios de avaliação de uma situação de aprendizagem remete o aluno ao desenvolvimento de uma nova situação desafiadora. 


\section{PROCEDIMENTOS METODOLÓGICOS}

Este estudo pode ser classificado como pesquisa descritiva, de abordagem qualitativa na forma de estudo de caso.

Em relação à abordagem qualitativa do problema, esta se justifica por ser uma forma adequada para entender a natureza de um fenômeno social (RICHARDSON, 2008). Para Creswell (2007), os procedimentos qualitativos apresentam um grande contraste em relação aos métodos quantitativos, pois os procedimentos qualitativos se baseiam em dados de textos e imagens, têm passos únicos na análise de dados e usam estratégias diversas de investigação.

Quanto ao estudo de caso, Barros e Lehfeld (2003) define como uma metodologia de estudo que se volta à coleta de informações sobre um ou vários casos particularizados.

"O estudo de caso caracteriza-se como caso único e é o preferido pelos pesquisadores que desejam aprofundar seu conhecimento a respeito de determinado caso específico" (BEUREN, 2010, p.84).

Neste contexto, o objeto do presente estudo foi o SENAI - Departamento Regional de Santa Catarina - uma instituição de educação profissional que atua em todos os níveis e modalidades da educação profissional, além de atuar na educação básica, por meio do ensino médio articulado com a educação profissional. Esta instituição possui 45 pontos de atendimento, distribuídos em oito regiões no Estado (litoral, vale, alto-vale, norte, planalto, meio oeste, oeste e sul), abrangendo a todos os municípios catarinenses. A escolha desse caso deve-se ao fato de ser uma instituição de educação profissionalizante consolidada em âmbito nacional, que adota desde o inicio da década de 2000 a metodologia de formação profissional com base em competências.

A população de pesquisa compreende grupo de colaboradores, especialistas do núcleo de educação e da área de gestão de pessoas lotados na unidade da Direção Regional do SENAI/SC. Estes grupos dão suporte a Alta Direção do SENAI na elaboração e implementação das estratégias e ações no âmbito da metodologia de formação profissional com base em competências na organização. Para Rudio (2006, p.49) o termo população designa a totalidade de indivíduo que possuem as mesmas características, definidas para um determinado estudo.

A amostra é parte da população, selecionada de acordo com uma regra ou plano (RÚDIO, 2006). A amostra deste estudo foi composta por 05especialistas em educação que participaram do processo de implantação da metodologia no Estado, a partir de 2000, e, 03 profissionais da área de $\mathrm{RH}$, responsáveis pelos programas de capacitação e disseminação das estratégias corporativas em âmbito interno. Trata-se de uma amostra não probabilística que foi selecionada por intencionalidade. Rudio (2006) estabelece que a amostra não probabilística de forma intencional é escolhida através de estratégia adequada em que são escolhidos casos para "o bom julgamento" da população sob 
algum aspecto, não servindo, consequentemente, os resultados obtidos nesta amostra, para se fazer uma generalização para a população "normal".

O método de coleta foi entrevista individual em profundidade,semiestruturada apoiada por roteiro de entrevista (instrumento de coleta). Para os profissionais da amostra, essa entrevista foi aplicada de forma pessoal no ambiente natural dos entrevistados. O roteiro de entrevista foi estruturado com perguntas abertas elaboradas a partir dos objetivos do estudo e da revisão da literatura. Foi realizada a verificação do roteiro antes da sua aplicação para avaliar sua aplicabilidade e identificar possíveis melhorias.

O método de análise dos dados foi por meio da transcrição dos depoimentos das entrevistas. Para Vergara (2010, p.7), “a análise de conteúdo é uma técnica para o tratamento de dados que visa identificar o que está sendo dito a respeito de determinado tema".

\section{ANÁLISE DOS RESULTADOS}

\subsection{Estratégias e ações empregadas pelo SENAI/SC na implantação da metodologia de formação profissional com base em competências}

O SENAI/SC, a partir de 2000, realiza as primeiras ações concretas para a implementação da metodologia de formação profissional com base em competências. O quadro 01 apresenta as principais estratégias e ações desenvolvidas no período de 1999 a 2012.

Quadro 1: Estratégiase ações de implementação da metodologia de formação profissional com base em competências no SENAI/SC no período de 1999 a 2012

\begin{tabular}{|l|l|}
\hline ANO & \multicolumn{1}{c|}{ ESTRATÉGIAS/AÇÕES } \\
\hline 1999 & $\begin{array}{l}\text { - } \begin{array}{l}\text { O SENAI/SCfoiintegrante do grupo piloto de elaboração dos documentos } \\
\text { norteadores da metodologia. }\end{array} \\
2002\end{array}$ \\
2003 & $\begin{array}{l}\text { Projeto pilotona metodologia de formação profissional com base em competências, } \\
\text { no curso superior de tecnologia em automação no SENAI Florianópolis. }\end{array}$ \\
2004 & $\begin{array}{l}\text { Primeiro ciclo estadual de capacitação na metodologia de formação profissional } \\
\text { com base em competências. }\end{array}$ \\
2005 & $\begin{array}{l}\text { O SENAI/SC foi sede de capacitação nacional de Multiplicadores das Metodologias } \\
\text { de Formação com base em competências realizada para a região Sul. }\end{array}$ \\
\hline $\begin{array}{l}\text { Seminário de "Avaliação de Competências na Formação Profissional". } \\
\text { Seminário de "Formação por Competências". }\end{array}$ \\
\hline
\end{tabular}




\begin{tabular}{|c|c|}
\hline ANO & ESTRATÉGIAS/ \\
\hline 2006 & $\begin{array}{l}\text { - } \quad \text { Projeto “Pressupostos para uma Educação de Qualidade." } \\
\text { - Projeto “Conexão SENAI" - Série Educação Por Competências. } \\
\text { - Segundo ciclo estadual de capacitação na Metodologia de formação profissional } \\
\text { com base em competências. }\end{array}$ \\
\hline 2007 & $\begin{array}{l}\text { - Iniciativa Estratégica: Fortalecer e Disseminar o Programa Educação por } \\
\text { Competências }\end{array}$ \\
\hline 2008 & $\begin{array}{l}\text { - Programa Educação em Movimento - Consolidar a Educação por Competências. } \\
\text { - Io Seminário de Formação Pedagógica “Teoria Histórico-Cultural”. } \\
\text { - IIo Seminário de Formação Pedagógica “Educação Por Competências". } \\
\text { - IIIo Seminário de Formação Pedagógica “Planejamento Pedagógico" e } \\
\text { "Problematização". } \\
\text { - Implementação de Iniciativa Estratégica: Consolidar Modelo EPC. }\end{array}$ \\
\hline 2009 & $\begin{array}{l}\text { - IVo Seminário de Formação Pedagógica "Avaliação por Competências". } \\
\text { - Iniciativa Estratégica: Reestruturação de cursos Regulares. }\end{array}$ \\
\hline 2010 & $\begin{array}{l}\text { - Workshop "Gestão da Educação Profissional com base em Competências". } \\
\text { - Módulos de Formação Pedagógica "Práticas Pedagógicas" e "Avaliação por } \\
\text { Competências." } \\
\text { - Projeto Aplicativo PDL "Sistematização de Projetos Integradores" }\end{array}$ \\
\hline 2011 & $\begin{array}{l}\text { - Workshop "Brockton High School". } \\
\text { - Capacitação nacional em: "Práticas Pedagógicas - Situações de Aprendizagem". } \\
\text { - Programa Academia SENAI: "Itinerários Formativos Docentes". }\end{array}$ \\
\hline 2012 & $\begin{array}{l}\text { - Programa Educação em Movimento (Atualização). } \\
\text { - Capacitação docente na elaboração e implementação de situações de } \\
\text { aprendizagem. } \\
\text { - Projeto Aplicativo PDL "Como Consolidar a Metodologia de Educação por } \\
\text { Competências no SENAI/SC". } \\
\text { - Blog "A Escola que Queremos". }\end{array}$ \\
\hline
\end{tabular}

Fonte: SENAI/SC Núcleos de educação e de gestão de pessoas da direção regional (2012). 
Entre as estratégias e ações citadas no quadro 01, algumas ganharam status de "Programa" pela instituição e, muitas atividades foram decorrentes destes programas. Entre os principais programas têm-se: Programa Conexão SENAI; Programa Educação em Movimento e Programa Academia SENAI.

Além destes programas, uma estratégia de grande impacto desenvolvida foi a criação do Blog "A Escola que Queremos", canal direto de comunicação com os docentes e coordenadores.

\subsubsection{Programa Conexão SENAI}

O Programa Conexão SENAI é um portal de serviços dedicado à formação continuada dos colaboradores do SENAI/SC. Sua principal ferramenta de suporte é o ambiente virtual de aprendizagem do SENAIvirtual.Trata-se de uma iniciativa que busca incentivar e criar condições ao auto-desenvolvimento dos colaboradores, contribuindo para a gestão eficaz e manutenção do capital intelectual da instituição.

A Educação com base em competências faz parte de uma das séries do Conexão SENAI. Nesta série, são abordados os princípios para formação com base em competências; práticas pedagógicas com base em competências; e, elaboração de perfis profissionais com base em competências. Apresenta-se na figura 3 a identidade visual deste Programa.

Figura 2: Programa Programa Conexão SENAI/SC

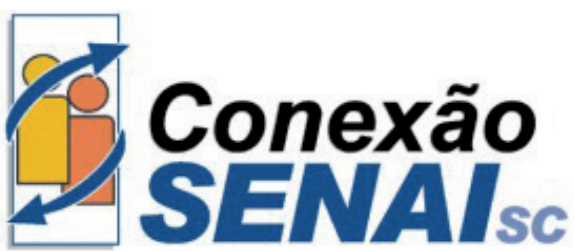

Fonte: Intranet SENAI/SC (2012)

O Programa CONEXÃO é uma das ferramentas que visa suprir as demandas por capacitação, identificadas no Levantamento de Necessidades de Treinamento (LNT), além de promover o auto-desenvolvimento dos colaboradores da organização. 


\subsubsection{Programa Educação em Movimento}

Criado em 2008 com objetivo de promover a melhoria contínua dos processos educacionais da instituição, o Programa Educação em Movimento, visa aqualidade dos cursos por meio da consolidação da Educação com base em Competências. Este programa foi estruturado em seis dimensões que se inter-relacionam, a saber: Projetos de Cursos; Recursos Didáticos; Formação Continuada; Processos Didáticos-Pedagógicos; Sistema de Avaliação; e, Documentos Norteadores, conforme se observa na figura 4.

Figura 3: Programa Educação em Movimento

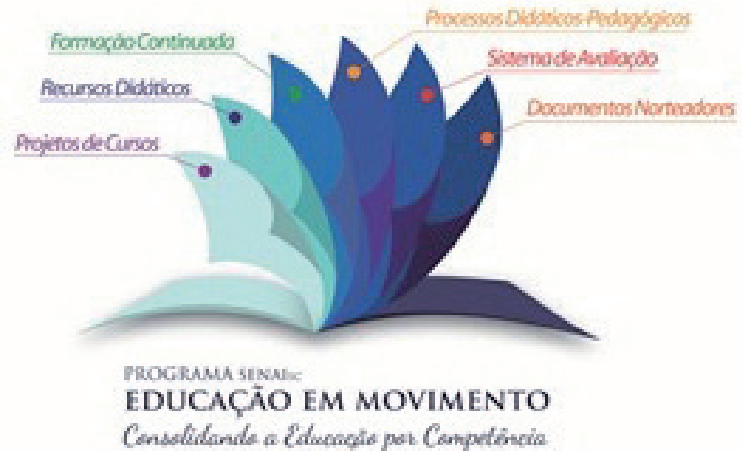

Fonte: Intranet SENAI/SC (2012)

A dimensão de Projeto de curso visa atender as necessidades de Educação Profissional do mundo do trabalho, por meio da elaboração de projetos de cursos corporativos desenvolvidos a partir da análise de perfil profissional e do desenho curricular, definidos em comitês técnicos setoriais, contribuindo para a qualidade do processo educacional e elevando a competitividade da indústria.

A segunda dimensão Recursos Didáticos tem por objetivo criar, selecionar e utilizar recursos didáticos contemplando as novas tecnologias da informação e comunicação aplicadas à educação, agregando valor ao processo de ensino e de aprendizagem, de modo a conferir diferencial competitivo nos serviços de Educação.

Formação Continuadas é a terceira dimensão do programa cujo objetivo é desenvolver competências promovendo a geração, a difusão e a aplicação do conhecimento organizacional, por meio de um processo de aprendizagem ativo e contínuo.

Os processos didáticos-pedagógicos, quarta dimensão, visam integrar os estudantes em ações pedagógicas que contribuam para o desenvolvimento das competências requeridas pelo mundo do trabalho, nos diferentes níveis e modalidades de ensino. 
A dimensão Sistema de avaliação tem por objetivo verificar a eficácia dos serviços educacionais para orientar a gestão da Instituição nas decisões a serem tomadas, visando alcançar a efetividade nos processos de educação.

Documentos Norteadores, sexta dimensão, visa sistematizar orientações para os processos educacionais com base nos requisitos legais e normativos.

\subsubsection{Programa Academia SENAI}

A Academia SENAI é um sistema de desenvolvimento de pessoas pautado pela gestão por competências alinhada às estratégias da Organização. É um polo permanente para o desenvolvimento dos colaboradores e aprendizagem para a Organização.Como objetivos específicos a Academia pretende:

a) institucionalizar a cultura de aprendizagem contínua, visando proporcionar a aquisição e desenvolvimento de competências vinculadas às estratégias organizacionais assegurando vantagens competitivas permanentes ao SENAI;

b) promover a geração, difusão e aplicação do conhecimento organizacional;

c) promover oportunidades de aprendizagem que dêem suporte ao SENAI para o alcance dos objetivos críticos do negócio;

d) ser um foco de perpetuidade da visão, missão, valores e cultura organizacional;

e) proporcionar a atualização técnica e tecnológica dos colaboradores do SENAI;

f) certificar docentes e consultores, reconhecendo suas competências técnicas;

g) mapear as funções estratégicas para a Organização, desenvolvendo novas lideranças e capacitando as já instituídas;

h) realizar parcerias com instituições de ensino, institutos de tecnologia e certificadoras de renome nacional e internacional para a capacitação e certificação dos colaboradores.

\subsubsection{Blog A Escola Que Queremos}

Os desafios colocados para as instituições com propósitos educacionais são muitos, pois muitas são as possibilidades de atuação e muitas são as variáveis intervenientes. A definição da escola que queremos, dos caminhos que precisamos percorrer para proporcionar aos nossos alunos uma formação que os prepare para o mundo do trabalho e para uma vida cidadã, é uma das alternativas identificada pela organização para superar esses desafios. 
A Escola que queremos é um espaço institucional, democrático e acessível a todos os colaboradores da organização que pretende promover e instigar a reflexão sobre a temática educacional. Neste espaço, os colaboradores podem refletir, opinar e sugerir ideias que contribuam para um novo modelo educacional, adaptado às mudanças rápidas da tecnologia e às competências exigidas pelo mundo do trabalho. Apresenta-se na figura 5 o leiaute do blog a escola que queremos.

Figura 4: Blog "A escola que queremos"

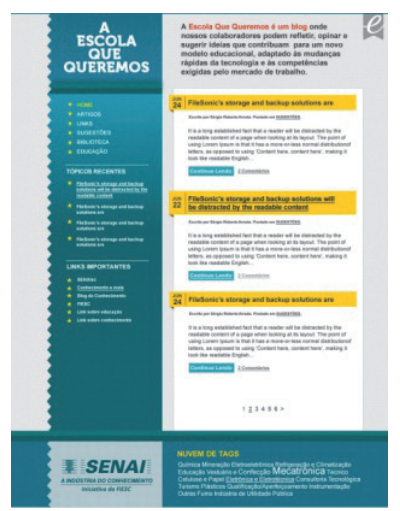

Fonte: Intranet SENAI/SC (2012)

\subsection{Resultados alcançados a partir da implementação das estratégias e ações mais relevantes}

Apresenta-se nos quadros 2 e 3 os principais eventos realizados, o seu ano de realização, o publico alvo e o número de colaboradores da organização que participaram dos eventos.

Quadro 2: Número de colaboradores capacitados na metodologia de formação profissional com base em competências

\begin{tabular}{|l|c|l|c|}
\hline \multicolumn{1}{|c|}{ EVENTO } & ANO & \multicolumn{1}{|c|}{ PÚBLICO ALVO } & FREQUÊNCIA \\
$\begin{array}{l}\text { Capacitação estadual - Metodologia de } \\
\begin{array}{l}\text { Formação Profissional com Base Em } \\
\text { Competências. }\end{array}\end{array}$ & 2003 & $\begin{array}{l}\text { Coordenadores } \\
\text { pedagógicos, de curso e } \\
\text { Docentes }\end{array}$ & $633^{*}$ \\
$\begin{array}{l}\text { Capacitação nacional-Multiplicadores } \\
\text { das Metodologias de Formação } \\
\begin{array}{l}\text { Profissional com Base Em } \\
\text { Competências. }\end{array}\end{array}$ & 2004 & $\begin{array}{l}\text { Coordenadores dos } \\
\text { Departamentos Regionais } \\
\text { do SENAI do PR, SC e RS }\end{array}$ & RGS - 7 \\
\hline
\end{tabular}




\begin{tabular}{|c|c|c|c|}
\hline EVENTO & ANO & PÚBLICO ALVO & FREQUÊNCIA \\
\hline $\begin{array}{l}\text { Capacitação estadual - Metodologia de } \\
\text { Formação Profissional com Base Em } \\
\text { Competências. }\end{array}$ & 2006 & $\begin{array}{l}\text { Coordenadores } \\
\text { pedagógicos, de curso e } \\
\text { Docentes }\end{array}$ & $238 * * *$ \\
\hline $\begin{array}{l}\text { Módulos de Formação Pedagógica - } \\
\text { Práticas Pedagógicas }\end{array}$ & $\begin{array}{c}2009 a \\
2012\end{array}$ & $\begin{array}{l}\text { Coordenadores } \\
\text { pedagógicos, de curso }\end{array}$ & 42 \\
\hline $\begin{array}{l}\text { Módulos de Formação Pedagógica - } \\
\text { Avaliação com base em competências. }\end{array}$ & $\begin{array}{c}2009 a \\
2012\end{array}$ & $\begin{array}{l}\text { Coordenadores } \\
\text { pedagógicos, de curso }\end{array}$ & 48 \\
\hline $\begin{array}{l}\text { Módulos de Formação Pedagógica - } \\
\text { Práticas Pedagógicas }\end{array}$ & $\begin{array}{c}2009 \text { a } \\
2012\end{array}$ & Docentes & 1.267 \\
\hline $\begin{array}{l}\text { Módulos de Formação Pedagógica - } \\
\text { Avaliação com base em competências. }\end{array}$ & $\begin{array}{c}2009 a \\
2012\end{array}$ & Docentes & 877 \\
\hline $\begin{array}{l}\text { Capacitação nacional - Práticas } \\
\text { Pedagógicas: Situações De } \\
\text { Aprendizagem. }\end{array}$ & 2011 & Apoio pedagógico & 6 \\
\hline $\begin{array}{l}\text { Capacitação estadual - Práticas } \\
\text { Pedagógicas: Situações De } \\
\text { Aprendizagem. }\end{array}$ & 2012 & $\begin{array}{l}\text { Coordenadores de curso e } \\
\text { docentes }\end{array}$ & 307 \\
\hline
\end{tabular}

Fonte: SENAI/SC Núcleos de educação e de gestão de pessoas da direção regional (2012).

* Informação coletada junto aos especialistas do núcleo de educação da direção regional que conduziram a capacitação estadual.

**Informação coletada junto aos especialistas do núcleo de educação da direção regional que participaram da capacitação nacional

***Informação coletada junto aos especialistas do núcleo de educação da direção regional que conduziram a capacitação estadual

Quadro 3: Número de colaboradores capacitados no Programa "CONEXÃO SENAl” no período de 2009 a 2012

\begin{tabular}{|c|c|l|c|}
\hline EVENTO & ANO & PÚBLICO ALVO & FREQUÊNCIA \\
\hline CONEXÃO - Módulo: Fundamentos de Educação & $\begin{array}{c}2009 \text { a } \\
2012\end{array}$ & $\begin{array}{l}\text { Colaboradores } \\
\text { da organização }\end{array}$ & 373 \\
CONEXÃO - Módulo: Educação Por Competências & 2009 a & $\begin{array}{l}\text { Colaboradores } \\
\text { da organização }\end{array}$ & 70 \\
\hline
\end{tabular}

Fonte: SENAI/SC Núcleo de gestão de pessoas da direção regional - set/2012 
No período de 2005 a 2010, o SENAI/SC realizou uma série de eventos com intuito de consolidar a metodologia de formação profissionalcom base em competências no Estado. No quadro 4 estão os principais eventos realizados, o seu ano de realização, o público alvo e o número de colaboradores da instituição que participaram dos eventos.

Quadro 4: Principais eventos realizados pelo SENAI/SC para consolidar a Educação com Base em Competências no período de 2005 a 2010

\begin{tabular}{|c|c|c|c|}
\hline EVENTO & ANO & PÚBLICO ALVO & FREQUÊNCIA \\
\hline $\begin{array}{l}\text { Seminário de "Avaliação de } \\
\text { Competências na Formação } \\
\text { Profissional" }\end{array}$ & 2005 & $\begin{array}{l}\text { Coordenadores } \\
\text { pedagógicos e } \\
\text { especialistas em } \\
\text { educação }\end{array}$ & 36 \\
\hline $\begin{array}{l}\text { lo Seminário de Formação } \\
\text { Pedagógica "Teoria Histórico- } \\
\text { Cultural" }\end{array}$ & 2008 & $\begin{array}{l}\text { Coordenadores } \\
\text { Pedagógicos e } \\
\text { Especialistas em } \\
\text { Educação }\end{array}$ & 41 \\
\hline $\begin{array}{l}\text { Ilo Seminário de Formação } \\
\text { Pedagógica "Educação Por } \\
\text { Competências" }\end{array}$ & 2008 & $\begin{array}{l}\text { Coordenadores } \\
\text { Pedagógicos }\end{array}$ & 39 \\
\hline $\begin{array}{l}\text { IIIo Seminário de Formação } \\
\text { Pedagógica "Planejamento } \\
\text { Pedagógico" e "Problematização" }\end{array}$ & 2008 & $\begin{array}{l}\text { Coordenadores } \\
\text { Pedagógicos }\end{array}$ & 35 \\
\hline $\begin{array}{l}\text { IVo Seminário de Formação } \\
\text { Pedagógica "Avaliação por } \\
\text { Competências" }\end{array}$ & 2009 & $\begin{array}{l}\text { Coordenadores } \\
\text { pedagógicos, } \\
\text { coordenadores de } \\
\text { curso }\end{array}$ & 81 \\
\hline $\begin{array}{l}\text { Workshop "Gestão da Educação } \\
\text { Por Competências" }\end{array}$ & 2010 & $\begin{array}{l}\text { Coordenadores } \\
\text { pedagógicos, } \\
\text { coordenadores de } \\
\text { curso e especialistas } \\
\text { em educação }\end{array}$ & $56^{*}$ \\
\hline Workshop Brockton High School & 2011 & $\begin{array}{l}\text { Diretores } \\
\text { coordenadores }\end{array}$ & 73 \\
\hline
\end{tabular}

Fonte: SENAI/SC Núcleo de educação e de gestão de pessoas da direção regional(2012).

*Informação coletada junto aos especialistas do núcleo de educação da direção regional 
No âmbito do Programa "Academia SENAI", a organização realizou no período de janeiro a julho de 2012, osmódulos dos itinerários formativos para os docentes nas áreas de mecânica e eletricidade. 0 quadro 5 apresenta o ano de realização do evento, o público alvo e o número de colaboradores capacitados.

Quadro 5: Número de colaboradores capacitados no Programa "ACADEMIA SENAI"

\begin{tabular}{|c|c|c|c|}
\hline EVENTO & ANO & PÚBLICO ALVO & FREQUÊNCIA \\
\hline Módulo Eletricidade & 2012 & Docentes & 58 \\
Módulo.Mecânica & 2012 & Docentes & 47 \\
\hline
\end{tabular}

Fonte: SENAI/SC Núcleo de gestão de pessoas da direção regional (2012).

Para a implementação da metodologia de educação com base em competências, além das capacitações, a organização promoveu a reestruturação e atualização dos projetos de curso de todas as modalidades de educação profissional e do ensino médio. Esta atualização é imprescindível para o desenvolvimento de capacidades profissionais de acordo com o novo método educacional. 0 quadro 6 apresenta o número de cursos que foram reestruturados e/ou atualizados de acordo com a metodologia no período de 2008 a 2012.

Quadro 6: Número de cursos reestruturados e atualizados de acordo com a metodologia de formação profissional com base em competências

\begin{tabular}{|l|c|c|}
\hline \multicolumn{1}{|c|}{ MODALIDADE } & ANO & FREQUÊNCIA \\
\hline Reestruturação - Superior de Tecnologia & 2011 e 2012 & 10 \\
\hline Reestruturação - Técnico de Nível Médio & 2008 e 2009 & 30 \\
\hline Atualização - Técnico de Nível Médio & 2012 & 4 \\
Reestruturação - Aprendizagem Industrial & 2009 & 25 \\
\hline Reestruturação - FIC Pronatec & 2012 & 68 \\
Reestruturação - Ensino Médio & 2010 & $1^{*}$ \\
\hline
\end{tabular}

Fonte: SENAI/SC Núcleo de educação (2012).

* O projeto de curso do ensino médio é corporativo, ou seja, atende às 15 Unidades do SENAI/SC que ofertam esta modalidade de ensino.

Outro resultado importante para o SENAI/SC foi o número de acessos ao Blog "A escola que queremos". Esses acessos demonstram o envolvimento dos colaboradores da instituição, bem como a sua motivação com o tema. $O$ quadro 07 apresenta os acessos ao Blog no período de janeiro a julho de 2012. 
Quadro 7: Número de acessos ao blog "A escola que queremos"

\begin{tabular}{|l|c|}
\hline \multicolumn{1}{|c|}{ ACESSO AO BLOG } & FREQUÊNCIA \\
\hline Visitantes & 1.112 \\
\hline Número de acessos & 2.914 \\
\hline Número de páginas acessadas & 10.104 \\
\hline
\end{tabular}

Fonte: SENAI/SC Núcleo de educação(2012).

\subsection{Contribuições para o processo de ensino e aprendizagem.}

As principais contribuições para o processo de ensino e aprendizagem observados durante a implementação da metodologia SENAI para formação profissional com base em competências foram:

a) prática pedagógica centrada no sujeito e foco docente: a formação profissional com base em competências nos remetea uma reflexão no fazer pedagógico dentro da instituição, em que a prática pedagógica deveprivilegiar metodos centrados no sujeitoque aprende.O foco docente desloca-seentão do que vai ser ensinado para o que é preciso aprender. Neste novo contexto, o docente, que exercia o papel de mero transmissor de conhecimento, aparece como facilitador e mediador do processo de aprendizagem, oportunizando, desta forma, um melhor aprendizado para os alunos;

b) planejamento sistemático das atividades pedagógicas: o planejamento sistemático das atividades pedagógicas, pelos docentes, aparece como condição essencial para o bom desenvolvimento do processo de ensino e aprendizagem, tornando-se uma das principais contribuições da implementação da metodologia de educação profissional com base em competências para a instituição. É no planejamento docente que a instituição consegue identificar as principais lacunas entre o perfil profissional, o desenho curricular e a prática docente. Durante o planejamento, os princípios da metodologia SENAI de formação profissional com base em competências são colocados em prática, tais como a interdisciplinaridade, a contextualização, a recorrência, a modularização, entre outros;

c) situações de aprendizagem: situações de aprendizagem são situações desafiadoras que proporcionam o desenvolvimento de atividades de forma contextualizadas e interdisciplinares que auxiliam na transferência dos conhecimentos para os alunos, proporcionando o desenvolvimento de uma aprendizagem significativa em que confere significado aos conhecimentos e práticas trabalhadas pelos professores em sala. No que se refere a perspectiva interdisciplinar, percebe-se que a metodologia de educação profissional 
com base em competências rompe o paradigma de uma visão fragmentada e estanque das disciplinas. Este rompimento contribui de forma expressiva para a prática pedagógica, enriquecendo o desenvolvimento de projetos interdisciplinares, de pesquisas, de resolução de situações-problema e de desafios reais do mundo do trabalho;

d) apropriação das competências: outra grande contribuição da implantação da metodologia de formação profissional com base em competências é a apropriação, por parte dos alunos, das competências necessárias para inserção no mundo do trabalho, de acordo com o perfil profissional estabelecido pelo comitê técnico setorial. Neste sentido, a instituição insere no mercado, profissionais cada vez mais capacitados, contribuindo, desta forma, para o aumento da produtividade e consequentemente da competitividade da indústria brasileira.

\section{CONSIDERAÇÕES FINAIS}

Este estudo buscou apresentar quais as estratégias, decorrentes da implantação da metodologia SENAI de formação profissional com base em competências, contribuem de forma significativa para o processo de ensino e aprendizagem dos alunos.

Desta forma, com base na pesquisa descritiva apresentada, identificou-se que desde 1999, o SENAI/SC desenvolve estratégias e ações para a implementação desta metodologia no Estado. Entre estas, destaca-se a criação de programas cooporativos como: Conexão SENAI; Educação em Movimento e Academia SENAI. Além destes programas, destaca-se também a criação do Blog a Escola que Queremos.

Constatou-se na pesquisa, a preocupação da instituição quanto à capacitação de seus colaboradores. Esta preocupação é evidenciada pelo número expressivo de capacitações realizadas no âmbito da metodologia. No péríodo de 2003 a 2012 foram capacitados3.993 colaboradores, sendo 3.441 em capacitações estadual e/ou nacional,447 no Programa Conexão, e 105 no Programa AcademiaSENAI.

Em relação aos principais eventos realizados pelo SENAI/SC para implementar a educação com base em competências, identificou-se, no período de 2005 a 2012, cinco Seminários e dois Workshops. Nestes eventos 361 colaboradores tiveram a oportunidade de ampliar seus conhecimentos sobre a formação pedagógica, o planejamento pedagógico, a problematização, e a gestão da educação com base em competências.

A reestruturação de cursos é uma ação fundamental para a implementação da metodologia de formação profissional com base em competências. Desta forma, verificou-se que o SENAI/SC reestruturou 138 cursos a partir de 2008, sendo 10 cursos superiores de tecnologia, 30 cursos técnicos, 25 cursos de aprendizagem industrial, 68 cursos de qualificação profissional e 1 curso do ensino médio. 
Em relação ao blog A Escola que Queremos, constatou-se 1.112 visitantes no período de janeiro a julho de 2012. Estes visitantes realizaram 2.914 acessos, em 10.104 páginas no blog.

Como contribuições, este estudo apresenta um resgate temporal da implementação da metodologia no SENAI/SC, apresentando as principais estratégias e ações, o que auxiliar no desenvolvimento e implementação de novas estratégias e ações pela instituição, ou da sistematização de estratégias e ações já desenvolvidas.

Como limitação da pesquisa, cita-se o baixo número de registros das ações desenvolvidas nos primeiros anos de implementação da metodologia.

Para estudos futuros, recomenda-se explorar o papel do gestor na implementação da metodologia SENAI de formação profissional com base em competências. Outra recomendação é a implementação da filosofia do PDCA no processo de ensino e aprendizagem com base em competências.

\title{
SENAI METHODOLOGY FOR VOCATIONAL TRAINING BASED ON COMPETENCE: A CASE STUDY ON THE IMPLEMENTATION OF THIS METHOD IN THE REGIONAL DEPARTMENT OF SENAI SANTA CATARINA
}

\begin{abstract}
This article aims to identify which strategies, resulting from the implementation of the SENAI training methodology based on competences, contribute significantly to the process of teaching and learning for students at SENAI/SC. In this sense, the main strategies employed by the institution, the results achieved from the implementation of the most relevant strategies, and contributions to teaching and learning were identified. The study consists of a survey whose approach is descriptive and qualitative in the form of case study. It was found that the institution takes actions to implement the methodology since 1999 and that many corporate programs are a result of this implementation, such as: Connection Program, Program on Education in Movement, and Senai Academy. Also it is noteworthy that a significant number of events and trainings for employees are offered by the institution. Therefore, it is concluded that the implementation of the SENAI training methodology based on competences involves the development of actions that aimed at creating a culture focused on developing competences for the entire institution.
\end{abstract}


Keywords: Vocational Training. Methodology based on competence. Professional Profile. Curricular. Pedagogical practice.

\section{REFERÊNCIAS}

ANTUNES, Ana Bela et al. Terminologia de Formação Profissional. Lisboa: CIME, 2001.

BARROS, Aidil Jesus; LEHFELD, Neide Aparecida de Souza. Projeto de pesquisa: propostas metodológicas. 16. ed. Petrópolis: Vozes, 2003.

BEUREN, Ilse Maria (Org.). Como elaborar trabalhos monográficos em contabilidade: teoria e prática. 3. ed. São Paulo: Atlas, 2010.

BRASIL. Conselho Nacional de Educação. Parecer no.16, de 5 de outubro de 1999a. Diretrizes Curriculares Nacionais para a Educação Profissional de Nível Técnico. Disponível em: <http://portal.mec.gov.br/setec/arquivos/pdf_legislacao/tecnico/legisla_tecnico_ parecer1699.pdf>.Acesso em: 18 set. 2012.

. Conselho Nacional de Educação. Resolução no. 4, de 8 de dezembro de 1999b. Institui as Diretrizes Curriculares Nacionais para a Educação Profissional de Nível Técnico. Disponível em: <http://portal.mec.gov.br/setec/arquivos/pdf/RCNE_CEB04_99.pdf>. Acesso em: 18 set. 2012.

Ministério do Trabalho e Emprego. Instrução Normativa no 26, de 20 de dezembro de 2002. Altera o artigo 1ㅇ da Instrução Normativa no 26 de 20 de dezembro de 2001. Disponível em:<http://www1.sp.senac.br/hotsites/arquivos_materias/instrucao_ normativa_26\%2020-12-2002.pdf>. Acesso em: 21 set. 2012.

CANTO, Cleunisse Rauen De Luca. Contribuições da abordagem curricular por Competências para uma aprendizagem significativa. Revista E-Tech: Tecnologias para Competitividade Industrial, Florianópolis, v. 1, n. 2, p. 11-23, 2‥ Sem. 2008.

CRESWELL, John W. Projeto de pesquisa: métodos qualitativo, quantitativo e misto. 2. ed. Porto Alegre: Artmed, 2007.

FEDERAÇÃO DAS INDÚSTRIAS DO ESTADO DE SANTA CATARINA. Diretoria de Relações Industriais e Institucionais. Unidade de Política Econômica e Industrial. Desempenho e perspectivas da indústria catarinense: investimentos industriais 2011-2014: a economia em 2011 e perspectivas para 2012. Florianópolis, 2012. v. 12.

FERREIRA, Aurélio Buarque de Holanda. Novo dicionário aurélio da língua portuguesa. 4. ed.Curitiba: Positivo, 2009. 
FLEURY, Maria Tereza Leme; FLEURY, Afonso. Construindo o conceito de competência. Revista administração contemporânea, Curitiba, ed. especial, 2001.

MORAES, Carmen Sylvia Vidigal. Ações empresariais e formação profissional. São Paulo Perspec, São Paulo, v. 14, n. 2., p.82-100, abr./jun. 2000. Disponível em: <http://www. scielo.br/pdf/spp/v14n2/9792.pdf>. Acesso em: 18 set. 2012.

MORETTO, Vasco. Resolvendo situações complexas: avaliação do desempenho escolar focado no desenvolvimento de competências/habilidades. Revista Aprendizagem, Pinhais (PR), v. 3, n. 12, p. 30-31, maio/jun. 2009.

ORGANIZAÇÃO DAS NAÇÕES UNIDAS PARA A EDUCAÇÃO, CIÊNCIA E CULTURA. Educação um tesouro a descobrir: relatório para a UNESCO da Comissão Internacional sobre educação para o século XXI. Brasília,1998. Disponível em: <http://ftp.infoeuropa. eurocid.pt/database/000046001-000047000/000046258.pdf>. Acesso em: Acesso em: 21 set. 2012.

PERRENOUD, Philippe. Construir as competências desde a escola. Trad. Bruno Charles Magne. Porto Alegre: Artes Médicas Sul, 1999.

RICHARDSON, Roberto Jarry. Pesquisa social: métodos e técnicas. 3. ed. São Paulo: Atlas, 2008.

RUDIO, Franz Victor. Introdução ao projeto de pesquisa científica. 13.ed. Petrópolis/RJ: Vozes, 2006.

SERVIÇO NACIONAL DE APRENDIZAGEM INDUSTRIAL. Departamento Nacional. Elaboração de perfis profissionais por comitês técnicos setoriais. 3. ed. Brasília, DF: SENAI/DN, 2009a. 73 p. (Formação profissional baseada em competências; v.1). ISBN 9788575193044.

. Departamento Nacional. Elaboração de desenho curricular. 3. ed. Brasília, DF: SENAI/DN, 2009b. 64 p. (Formação profissional baseada em competências; v.2). ISBN 9788575193075.

Departamento Nacional. Norteador da prática pedagógica. 3. ed. Brasília, DF: SENAI/DN, 2009c. 107 p. (SENAI Formação Profissional por Competências; v3). ISBN 9788575193068.

Departamento Regional de Santa Catarina. Intranet. Disponível em:< https:// www.sc.senai.br/>. Acesso em: 21 set. 2012.[acesso restrito].

VERGARA, Sylvia Constant. Métodos de pesquisa em administração. 4.ed. São Paulo: Atlas, 2010.

VIEIRA, Denise Maria Rengel; BONETTI, Esther Aquemi. Gestão do processo educacional. Florianópolis, 2010. 


\section{SOBRE OS AUTORES}

Formado em Engenharia Elétrica pela UFRGS (1966), mestrado em Electrical
Machines and Power Systems pela Universidade de Londres (1970).
Especialização em Engenharia de Segurança do Trabalho pela UDESC (1974).
Sua carreira profissional iniciou-se como Professor do Departamento de
Engenharia Elétrica em 1968, onde permaneceu até 1994, quando se
aposentou como Professor Titular.Assumiu o posto de Chefe de Departamento
de Engenharia Elétrica da UFSC nos períodos de 1992 a 1994 e 1971 a 1974.
De 1975 a 1980 foi Diretor do Centro Tecnológico da UFSC e Diretor Presidente
da Fundação para Ensino de Engenharia-FEESC.
De 1990 a 1992 , desenvolveu atividades como Diretor de Desenvolvimento
Científico e Tecnológico do Governo do Estado.
No período de 1994 a 1996 foi pesquisador do CNPq/RHAE. Exerceu, também,
função de Diretor na Iniciativa Privada e Engenheiro na CELESC. Foi Diretor
Superintendente do SENAl-CTAI no período de 1996 a 1998.
Desde setembro de 1998 exerce o cargo de Diretor Regional do SENAI - Serviço
Nacional de Aprendizagem Industrial de Santa Catarina. É Conselheiro do
Conselho de Curadores da UFSC, do Conselho Estadual de Educação de SC
(CEE-SC) e do SEBRAE-SC.

Mestrando do Programa de Administração da Unisul. Possui graduação em
Tecnologia em Processos Industriais pela Universidade do Sul de Santa Catarina
(1992), especialização em Educação Especial Inclusiva pela Universidade Gama
Filho e especialização em Gestão de Organizaçães Educacionais e Inovação
Tecnológica pelo Instituto Catarinense de pós-graduação (ICPG). Foi integrante
do núcleo de educação da Direção Regional do SENAI na função de especialista
em educação por 10 anos, onde teve a oportunidade de atuar como interlocutor
estadual da metodologia de educação profissional com base em competências
no SENAI/SC. Atualmente é Diretor do SENAI em São Bento do Sul/SC.

